\title{
Associations of factor $\mathrm{VIII}_{\mathrm{c}}$, D-dimer and plasmin-antiplasmin with incident cardiovascular disease and all-cause mortality
}

\author{
Aaron R. Folsom, $\mathrm{MD}^{1}{ }^{,}$, Joseph A. C. Delaney, $\mathrm{PhD}^{2}$, Pamela L. Lutsey, $\mathrm{PhD}^{1}$, Neil A. Zakai, \\ MD $^{3,4}$, Nancy S. Jenny, PhD ${ }^{4}$, Joseph F. Polak, MD, MPH ${ }^{5}$, Mary Cushman, MD ${ }^{3,4}$, and for \\ the Multi-Ethnic Study of Atherosclerosis Investigators \\ ${ }^{1}$ Division of Epidemiology \& Community Health, School of Public Health, University of Minnesota, \\ Minneapolis, MN. \\ ${ }^{2}$ Collaborative Health Studies Coordinating Center, Department of Biostatistics, University of \\ Washington, Seattle, WA. \\ ${ }^{3}$ Department of Medicine, University of Vermont, Burlington, VT. \\ ${ }^{4}$ Department of Pathology, University of Vermont, Colchester, VT. \\ ${ }^{5}$ Department of Radiology, Tufts-New England Medical Center, Boston, MA.
}

\begin{abstract}
To examine the associations of three understudied hemostatic factors - D-dimer, factor VIII ${ }_{c}$, and antiplasmin (PAP) complex -- with incident CVD and all cause mortality in the Multi-Ethnic Study of Atherosclerosis (MESA) cohort. Hemostatic factors were measured at baseline in 45-84 year olds $(n=6,391)$ who were free of clinically recognized CVD. Over 4.6 years of follow-up, we identified 307 CVD events, 207 hard coronary heart disease (CHD) events, and 210 deaths. D-dimer, factor $\mathrm{VIII}_{\mathrm{c}}$, and PAP were not associated with CVD incidence after adjustment for other risk factors. In contrast, each factor was associated positively with total mortality, and D-dimer and factor VIII $_{c}$ were associated positively with cancer mortality. When modeled as ordinal variables and adjusted for risk factors, total mortality was greater by $33 \%(95 \% \mathrm{CI}=15-54 \%)$ for each quartile increment of D-dimer, $26 \%$ (11-44\%) for factor VIIIc, and 20\% (4-38\%) for PAP. This prospective cohort study did not find D-dimer, factor VIII $\mathrm{c}_{\mathrm{c}}$, or PAP to be risk factors for CVD. Instead, elevated levels of these three hemostatic factors were associated independently with increased risk of death. Elevated D-dimer and factor VIII $_{\mathrm{c}}$ were associated with increased cancer death.
\end{abstract}

\section{Keywords}

cancer; cardiovascular disease; CHD; D-dimer; factor VIII; plasmin-antiplasmin

\section{Introduction}

Several prospective epidemiological studies have assessed whether hemostatic factors may be risk factors for atherosclerotic cardiovascular disease (CVD) events [1]. While no hemostatic factor has emerged as being useful in routine clinical practice to predict CVD risk [1], more information is needed in many areas. For example, a few studies have suggested greater clotting factor VIII ${ }_{c}$ levels to be associated with elevated rates of CVD occurrence [2-4], but others

*Correspondence to: Aaron R. Folsom, MD, Division of Epidemiology \& Community Health, School of Public Health, University of Minnesota, 1300 South 2nd Street, Suite 300, Minneapolis, MN 55454 USA. Telephone: 612-626-8862; FAX: 612-624-0315; folso001@umn.edu. 
have not [5-7]. Even less epidemiological information exists associating CVD and plasminantiplasmin (PAP) complex, a marker of fibrinolysis [8]. More prospective data also could be helpful in clarifying the association between D-dimer and risk for future CVD. D-dimer, a fragment cleaved from cross-linked fibrin as part of fibrin clot degradation, reflects thrombin production and fibrinolysis. A meta-analysis has suggested an independent 1.7 fold increased risk of coronary heart disease (CHD) for the highest versus lowest tertile of D-dimer [9]. The specificity of the relation of these hemostatic factors with CVD nevertheless may be questioned, because they often are related positively to risk of other chronic conditions, such as cancer, or total mortality $[5,6]$, or show a moderate degree of correlation with markers of inflammation $[8,10,11]$.

In order to better understand the relations of these three hemostatic markers with incident CVD and all cause mortality, we analyzed the cohort of participants in the Multi-Ethnic Study of Atherosclerosis (MESA). We also evaluated whether these factors interact synergistically with measures of subclinical atherosclerosis, including elevated coronary artery calcium (CAC) and carotid intima media thickness (IMT), to augment the risk of CVD events in MESA.

\section{Results}

The MESA cohort at risk and with complete baseline information included 3013 men and 3378 women, with a mean age of 62 years at study enrollment (range 45-84 y). Their ethnic composition was 2434 (38\%) white, 1779 (28\%) African American, 1410 (22\%) Hispanic, and $768(12 \%)$ Chinese American. None had clinically recognized atherosclerotic disease (by design), but $7.8 \%$ reported a history of cancer not currently treated by radiation or chemotherapy. Median (interquartile range) values for D-dimer, factor $\mathrm{VIII}_{\mathrm{c}}$, and PAP were $0.20(0.24) \mu \mathrm{g} / \mathrm{mL}, 93$ (46) \%, and 4.4 (2.2) nM, respectively. Unadjusted Pearson correlations between these factors were $\mathrm{r}=0.25$ for D-dimer and PAP, $\mathrm{r}=0.10$ for D-dimer and factor $\mathrm{VIII}_{\mathrm{c}}$, and $\mathrm{r}=0.21$ for PAP and factor $\mathrm{VIII}_{\mathrm{c}}$.

As shown in Table I, D-dimer was positively associated with age, was lower in men than women, and varied by ethnicity and several other risk factors. D-dimer was also associated positively but modestly with fibrinogen (unadjusted $r=0.15)$, IL-6 $(r=0.12)$, and CRP $(r=$ 0.13). Supplemental Tables I and II [RECOMMENDED FOR THE JOURNAL'S WEBSITE] similarly show risk factor relations with factor $\mathrm{VIII}_{\mathrm{c}}$ and PAP. Both factor $\mathrm{VIII}_{\mathrm{c}}$ and PAP were positively associated with age, female gender, African American ethnicity. Factor $\mathrm{VIII}_{\mathrm{c}}$ was also notably associated positively with body mass index and diabetes and negatively with current smoking. PAP was associated positively with LDL and HDL cholesterol levels and inversely with body mass index, systolic blood pressure, statin use, and diabetes. Traditional risk factors were therefore taken into account when examining the independent association of the hemostatic factors with clinical outcomes. Factor $\mathrm{VIII}_{\mathrm{c}}$ was modestly correlated with fibrinogen (unadjusted $r=0.26)$, IL-6 $(r=0.17)$, and CRP $(r=0.15)$, and so was PAP $(r=0.38$ with fibrinogen, $r=0.16$ with IL-6, and $r=0.19$ with CRP).

Over a mean of 4.6 years of follow-up, we identified 307CVD events, 207 hard CHD events, and 210 deaths (22 deaths had underlying cause coded as CHD, 19 other CVD, 93cancer, 13 accidental, 55 other cause, and 8 unknown). Although D-dimer was positively associated with incidence of CVD and hard CHD in crude models, it was not associated independent of age, race, and sex, or other risk factors (Table II). Age, by far, explained most of the association (data not shown). A similar pattern was observed when D-dimer was alternatively modeled as a continuous variable or by examining the highest 10 percentile versus lowest 90 percentile. However, D-dimer was associated positively and strongly with risk of all cause mortality. In the risk factor adjusted model, hazard ratios for mortality were 1.00, 1.62, 1.91, and 2.57 across quartiles of D-dimer (Table II). This association was attenuated, but still significant, even after 
adjustment for fibrinogen, IL-6, and CRP. Numbers were too sparse for analysis of CVDspecific mortality, but in the risk factor adjusted model, hazard ratios for cancer mortality were $1.00,1.47(95 \% \mathrm{CI}=0.61-3.52), 3.03(1.41-6.51)$, and 3.07 (1.41-6.68) across D-dimer quartiles.

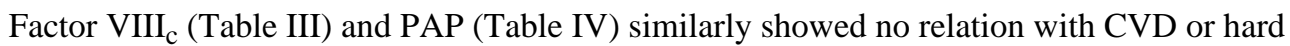
$\mathrm{CHD}$, independent of age and to a lesser degree sex and race. This was true for factor VIII $_{\mathrm{c}}$ or PAP modeled as categorical or continuous variables. Yet, both factor $\mathrm{VIII}_{\mathrm{c}}$ and PAP were associated with total mortality, with approximately 2 -fold gradients in risk factor adjusted mortality from quartile 1 to quartile 4 (Tables III and IV). For cancer mortality, hazard ratios in the risk factor adjusted model were 1.00, $1.32(95 \% \mathrm{CI}=0.66-2.67), 1.55(0.79-3.04)$, and 1.89 (0.98-3.64) across factor VIIIc quartiles. However, there was no association of cancer mortality with PAP: hazard ratios were 1.0, 1.89 (0.92-3.89), 1.29 (0.59-2.81), 1.62 (0.753.48) across PAP quartiles. When the three hemostatic factor quartiles were modeled as ordinal variables, adjusted for risk factors but not each other, total mortality was greater by $33 \%$ (95\% $\mathrm{CI}=15-54 \%)$ for each quartile increment of D-dimer, $26 \%(95 \% \mathrm{CI}=11-44 \%)$ for factor $\mathrm{VIII}_{\mathrm{c}}$, and $20 \%(95 \% \mathrm{CI}=4-38 \%)$ for PAP.

There was no effect modification between hemostatic factors and subclinical atherosclerosis measures in relation to CVD or hard CHD. All tests for multiplicative (and additive) interaction between a hemostatic factor and either CAC or IMT were statistically non-significant ( $p>0.05)$ in models adjusted for other risk factors and multiple testing. Correspondingly, there was no association between hemostatic factors and CVD or CHD within strata of CAC or IMT.

\section{Discussion}

In this prospective multiethnic study, plasma levels of D-dimer, factor $\mathrm{VIII}_{\mathrm{c}}$, and PAP were not independently associated with the occurrence of CHD or CVD events. However, these three factors were associated positively and independently with risk of total mortality. D-dimer and factor $\mathrm{VIII}_{\mathrm{c}}$ were also associated positively with cancer mortality. The associations with mortality were moderately strong and showed a graded response pattern.

A lack of association between CVD and CHD and these hemostatic factors, especially D-dimer, was unexpected. D-dimer has quite consistently been found associated with incident CVD [9], which suggests that increased fibrin formation is a CVD risk marker. Evidence for an independent relation between factor VIII $\mathrm{c}_{\mathrm{c}}$ or PAP and CVD has been less consistent [2-8]. One possible explanation for MESA observing no associations of these three factors with CVD may be limited statistical power to detect small associations. Yet, the number of CVD events was similar to many previous studies, and our risk factor adjusted findings for D-dimer and PAP do not even hint at any important associations. The numbers of events were larger for CVD incidence than for total mortality, for which an association was observed.

Another possibility for why our CVD findings contrast with previous studies relates to our inclusion and exclusion criteria. In contrast with most previous studies, MESA examined a multiethnic sample. MESA also rigorously excluded potential subjects who at baseline had any possible history of CVD. Most other prospective CVD studies have permitted subjects with angina or other forms of CVD to participate. Their cohorts also varied from ours in age and therefore probably in the prevalence of subclinical CVD. Thus, it is possible that elevated D-dimer, factor $\mathrm{VIII}_{c}$, or PAP was predictive of CVD events in previous studies because it was already elevated at baseline in participants with subclinical or early clinical CVD. Our study, however, found no interaction between subclinical CVD (elevated CAC or IMT) and hemostatic markers in association with clinical CVD events, albeit power may be limited for these analyses. 
The strong association between these hemostatic factors and total mortality was striking. Half of the deaths over this 4.6-year follow-up were due to cancer. Because cancer under treatment was a baseline exclusion factor, the cancer deaths would reflect aggressive cancers; MESA unfortunately does not have data on cancer incidence. Some previous prospective studies also reported that higher levels of D-dimer, factor $\mathrm{VIII}_{\mathrm{c}}$, PAP, and other hemostatic factors (e.g., fibrinogen) are markers of increased total mortality, noncardiovascular mortality, or cancer [5,6,12-14]. The Atherosclerosis Risk in Communities Study also found factor VIII $_{c}$ more strongly related to total mortality than to CHD incidence [6]: the risk factor adjusted relative risk of total mortality per standard deviation increment in factor $\mathrm{VIII}_{\mathrm{c}}$ was $1.28(95 \% \mathrm{CI}=$ $1.14-1.44)$ in men and 1.37 (1.21-1.55) in women, whereas the corresponding relative risks for CHD incidence were $1.01(0.86-1.18)$ in men and $0.99(0.81-1.23)$ in women. The meaning of the associations between hemostatic factors in ostensibly healthy adults and subsequent total mortality or cancer are not fully understood. It is possible that elevated hemostatic and inflammatory factors contribute in a general way to the causation of multiple diseases, including cancer, thereby leading to increased mortality $[13,15]$. On the other hand, reversecausality seems to be a more likely explanation, as cancer can have a long subclinical, latent period, and cancer [13,16-18] and other chronic conditions will cause increased intravascular coagulation or elevated markers of hemostasis and inflammation. Yet, we did not find a history of cancer not under treatment at baseline associated with the three hemostatic factors. Finally, it is possible that residual confounding, by extraneous factors not measured or adjusted for, may explain the observed association between the hemostatic factors and mortality.

As mentioned above, a limitation of our study is the number of events and the brief 4.6-year follow-up period. In addition, like many prior epidemiologic studies, we had only single baseline measures of the hemostatic factors. Biologic variability, leading to imprecision of single assessments of blood markers, generally tends to weaken the measured associations.

In summary, our study does not support an important role for D-dimer, factor $\mathrm{VIII}_{\mathrm{c}}$, or PAP in the etiology of CVD or in CVD risk prediction. Instead, elevated levels of these hemostatic factors were associated independently with increased risk of death, principally cancer death, in this cohort.

\section{Methods}

\section{MESA cohort and risk factor assessments}

MESA recruited 6,814 adults aged 45-84 from six Field Centers - Baltimore, MD; Chicago, IL; Forsyth County, NC; Los Angeles, CA; New York, NY; and St. Paul, MN - to a baseline examination between July 2000 and September 2002 [19]. They were Caucasians, African Americans, Hispanics, and Chinese Americans free of clinically recognized CVD. This was accomplished by excluding anyone who mentioned a doctor had told them that they had had a heart attack, angina, stroke, transient ischemic attack, or current atrial fibrillation; who took nitroglycerin; or who had had coronary bypass, angioplasty, heart valve replacement, pacemaker or defibrillator implantation, or other cardiovascular surgery. Subjects with any history of cancer treated with chemotherapy or radiation, or currently having another serious medical condition were also excluded. MESA conducted three subsequent examinations of the cohort between 2002 and 2007. Institutional Review Boards at each site approved the study, and all participants gave written informed consent.

Centrally-trained clinical teams collected information on cardiovascular risk factors during the baseline examination. They measured resting blood pressure three times in seated participants with a Dinamap model Pro 1000 automated oscillometric sphygmomanometer (Critikon,

Tampa, FL). They measured body mass index and assessed current alcohol intake and physical activity by questionnaires. All current medications were recorded. 
Fasting blood samples were collected, processed, and stored following a standardized protocol [20]. The Laboratory for Clinical Biochemistry Research (University of Vermont, Burlington, VT, USA) quantified factor VIII coagulant activity $\left(\mathrm{VIII}_{\mathrm{c}}\right)$ by measuring the clot time of a sample in factor VIII $_{\mathrm{c}}$ deficient plasma in the presence of activators utilizing the Sta-R analyzer (STA-Deficient VIII; Diagnostica Stago, Parsippany, NJ). The results are given as percent factor VIII, with reported normal plasma range of factor VIII in the adult population between 60 and $150 \%$. The factor VIII $_{c}$ standard curve is linear in a limited range, so samples were diluted more than usual (1/40) to allow more of them to be analyzed without further redilution. However, this resulted in overall higher factor $\mathrm{VIII}_{\mathrm{c}}$ values than are seen with the original 1/10 dilution. To correct for this, we analyzed 98 samples using both dilutions and analyzed the data by regression: Corrected Value $=0.56$ Measured Value $+7.1 ; \mathrm{R}=0.78$, a value consistent with the repeatability of a clot-based factor assay. Based on this analysis, the MESA factor VIII $\mathrm{C}_{\mathrm{c}}$ data were corrected using this relation. The laboratory measured D-dimer by an immunoturbidometric method on the Sta-R analyzer (Liatest D-DI; Diagnostica Stago, Parsippany, NJ, USA) and PAP by a two-site enzyme-linked immunosorbent assay (ELISA) that utilizes two monoclonal antibodies [21]. Fibrinogen and C-reactive protein (CRP) were measured by immunonephelometry using a BNTMII nephelometer (N Antiserum to Human Fibrinogen and N High Sensitivity CRP; Dade Behring Inc., Deerfield, IL, USA), and interleukin-6 (IL-6) by ultra-sensitive ELISA (Quantikine HS Human IL-6 Immunoassay; R $\&$ D Systems, Minneapolis, MN, USA). The average analytic coefficients of variation (CVs) for factor VIII $\mathrm{c}_{\mathrm{c}}$, D-dimer, PAP, CRP, and IL-6 were 10\%, 8\%, 2\%, 3\%, and 6\%, respectively.

The central laboratory also measured total and HDL-cholesterol and glucose levels from blood samples obtained after a 12-hour fast. We defined diabetes as fasting glucose $\geq 6.99 \mathrm{mmol} / \mathrm{L}$ $(126 \mathrm{mg} / \mathrm{dL})$ or use of hypoglycemic medication; impaired fasting glucose was defined as 5.55$6.98 \mathrm{mmol} / \mathrm{L}(100-125 \mathrm{mg} / \mathrm{dL})$.

As described elsewhere [22], at baseline field centers scanned for CAC by chest-computed tomography, twice in succession, using either a cardiac-gated electron-beam computed tomography scanner or a multi-detector computed tomography system. A radiologist or cardiologist read all CT scans at a central reading center (Los Angeles Biomedical Research Institute at Harbor-UCLA in Torrance, CA) using an interactive scoring system similar to that of Yaghoubi et al. [23] We used the average phantom-adjusted Agatston score [22] for the two scans in all analyses.

At baseline, trained technicians in each Field Center performed B-mode ultrasonography of the right and left near and far walls of the internal carotid and common carotid arteries [24]. An ultrasound reading center (Department of Radiology, New England Medical Center) measured maximal IMT of the internal and common carotid sites as the mean of the maximum IMT of the near and far walls of the right and left sides. For analysis, we used a composite Z score for overall maximal IMT by summing the two carotid IMT sites after standardization (subtraction of the mean and division by the standard deviation of each measure) and then dividing by the standard deviation of the sum.

\section{CVD follow-up}

We followed the cohort for incident CVD events for a median of 4.6 years (max $6.5 \mathrm{y}$ ). At intervals of 9-12 months, a telephone interviewer contacted each participant to inquire about interim hospital admissions, cardiovascular outpatient diagnoses, and deaths. In order to verify self-reported diagnoses, we requested copies of all death certificates and medical records for hospitalizations and outpatient cardiovascular diagnoses. We also conducted next-of-kin interviews for out of hospital cardiovascular deaths. We obtained records on an estimated $98 \%$ of reported hospitalized cardiovascular events and some information on $95 \%$ of reported outpatient diagnostic encounters. 
Two physicians, blinded to information from MESA examinations, independently reviewed and classified CVD events and assigned incidence dates. If, after review and adjudication, disagreements persisted, a full mortality and morbidity review committee made the final classification. Reviewers classified myocardial infarction as definite, probable or absent, based primarily on combinations of symptoms, ECG, and cardiac biomarker levels. Reviewers graded angina based on their clinical judgment as definite, probable or absent. They classified CHD or CVD death as present or absent based on hospital records and interviews with families. Definite fatal CHD required an MI within 28 days of death, chest pain within the 72 hours before death, or a history of CHD and the absence of a known non-atherosclerotic or noncardiac cause of death. Neurologists reviewed and classified stroke as present if there was a focal neurologic deficit lasting 24 hours or until death, with a clinically relevant lesion on brain imaging, and no nonvascular cause.

For this report, we defined "hard CHD" as definite and probable myocardial infarction, definite coronary heart disease death. We defined CVD as hard CHD, resuscitated cardiac arrest, definite angina, probable angina associated with coronary revascularization, stroke, or other atherosclerotic CVD death. Follow-up was from the baseline examination until the first CVD event, loss to follow-up, death, or else through the sixth follow-up phone interview (October 2005 to May 2007).

\section{Statistical analysis}

Our hypothesis was that factor $\mathrm{VIII}_{\mathrm{c}}$, plasmin-antiplasmin, and D-dimer would be associated positively with incident CVD. Secondary study endpoints were hard CHD and total mortality.

From the 6,814 MESA baseline participants, we successively excluded 6 with prevalent CVD, 24 using warfarin at baseline, 205 with missing data on the three hemostatic factors, and 188 with missing baseline data on study covariates, leaving 6,391 participants followed for incident CVD. The baseline associations between quartiles of hemostatic factors and baseline covariates (means or percents) were assessed and adjusted for age, race, and sex using linear models. Hazard ratios of study outcomes for hemostatic factors, modeled as quartiles or continuous variables, were calculated using the following Cox proportional hazard models: (1) crude, (2) adjusted for baseline age, sex, and race (African American, Hispanic, Chinese American, or white), and (3) additionally adjusted for other risk factors: baseline body mass index, systolic blood pressure, antihypertensive medications (yes, no), LDL and HDL cholesterol, statin use (yes, no), usual alcohol intake (drinks/wk), smoking status (current, ex, never), cigarette packyears, exercise (MET-h/wk), and glycemia status (diabetes, impaired fasting glucose, or normal). Another model 6 added other baseline plasma hemostatic or inflammatory markers: fibrinogen, IL-6, and CRP. In supplemental analyses, we also modeled the hemostatic factors as continuous variables on their natural scale and as ordinal variables with values of $0,1,2$, and 3 representing successive quartile groups.

Potential interactions (effect modification) between the hemostatic factors and both CAC (present/absent) and IMT (continuous) were tested using cross-product terms (along with main effect terms) in risk factor adjusted Cox models for each study outcome.

\section{Supplementary Material}

Refer to Web version on PubMed Central for supplementary material.

\section{Acknowledgments}

This research was supported by contracts N01-HC-95159 through N01-HC-95165 and N01-HC-95169 from the National Heart, Lung, and Blood Institute. 
The authors thank the other investigators, the staff, and the participants of the MESA study for their valuable contributions. A full list of participating MESA investigators and institutions can be found at http://www.mesa-nhlbi.org.

\section{References}

1. Lowe GDO. Can haematological tests predict cardiovascular risk? The 2005 Kettle Lecture. Br J Haematol 2006;133:232-250. [PubMed: 16643425]

2. Meade TW, Cooper JC, Stirling Y, et al. Factor VIII, ABO blood group and the incidence of ischaemic heart disease. Br J Haematol 1994;88:601-607. [PubMed: 7819072]

3. Zakai NA, Katz R, Jenny NS, et al. Inflammation and hemostasis biomarkers and cardiovascular risk in the elderly: the Cardiovascular Health Study. Thromb Haemost 2007;5:1128-1135.

4. Rumley A, Lowe GDO, Sweetnam PM, et al. Factor VIII, von Willebrand factor and the risk of major ischaemic heart disease in the Caerphilly Study. Br J Haematol 1999;105:110-116. [PubMed: 10233372]

5. Meade TW, Mellows S, Brozovic M, et al. Haemostatic function and ischaemic heart disease: principal results of the Northwick Park Heart Study. Lancet 1986;ii:533-537. [PubMed: 2875280]

6. Folsom AR, Wu KK, Rosamond WD, et al. Prospective study of hemostatic factors and incidence of coronary heart disease: the Atherosclerosis Risk in Communities (ARIC) Study. Circulation 1997;96:1102-1108. [PubMed: 9286936]

7. Smith A, Patterson C, Yarnell J, et al. Which hemostatic markers add to the predictive value of conventional risk factors for coronary heart disease and ischemic stroke? The Caerphilly Study. Circulation 2005;112:3080-3087. [PubMed: 16286603]

8. Cushman M, Lemaitre RN, Kuller LH, et al. Fibrinolytic activation markers predict myocardial infarction in the elderly. The Cardiovascular Health Study. Arterioscler Thromb Vasc Biol 1999;19:493-498. [PubMed: 10073948]

9. Danesh J, Whincup P, Walker M, et al. Fibrin D-dimer and coronary heart disease: prospective study and meta-analysis. Circulation 2001;103:2323-2327. [PubMed: 11352877]

10. Sakkinen PA, Cushman M, Psaty BM, et al. Relationship of plasmin generation to cardiovascular disease risk factors in elderly men and women. Arterioscler Thromb Vasc Biol 1999;19:499-504. [PubMed: 10073949]

11. Conlan MG, Folsom AR, Finch A, et al. Associations of Factor VIII and von Willebrand Factor with age, race, sex, and risk factors for atherosclerosis. The Atherosclerosis Risk in Communities (ARIC) Study. Thromb Haemost 1993;70:380-385. [PubMed: 8259533]

12. Danesh J, Lewington S, Thompson SG, Lowe GD, et al. Fibrinogen Studies Collaboration. Plasma fibrinogen level and the risk of major cardiovascular diseases and nonvascular mortality: an individual participant meta-analysis. JAMA 2005;294:1799-1809. [PubMed: 16219884]

13. Franchini M, Montagnana M, Targher G, et al. Pathogenesis, clinical and laboratory aspects of thrombosis in cancer. J Thromb Thrombolysis 2007;24:29-38. [PubMed: 17396228]

14. Miller GJ, Bauer KA, Howarth DJ, et al. Increased incidence of neoplasia of the digestive tract in men with persistent activation of the coagulant pathway. J Thromb Haemost 2004;2:2107-2114. [PubMed: 15613014]

15. Medcalf RL. Fibrinolysis, inflammation, and regulation of the plasminogen activating system. J Thromb Haemost 2007;5 Suppl 1:132-142. [PubMed: 17635719]

16. De Cicco M. The prothrombotic state in cancer: Pathogenic mechanisms. Crit Rev Oncol Hematol 2004;50:187-196. [PubMed: 15182825]

17. Rickles FR, Falanga A. Molecular basis for the relationship between thrombosis and cancer. Thromb Res 2001;102:V215-V224. [PubMed: 11516455]

18. Goad KE, Gralnick HR. Coagulation disorders in cancer. Hematol Oncol Clin North Am 1996;10:457-484. [PubMed: 8707764]

19. Bild DE, Bluemke DA, Burke GL, et al. Multi-Ethnic Study of Atherosclerosis: Objectives and design. Am J Epidemiol 2002;156:871-881. [PubMed: 12397006]

20. Cushman M, Cornell ES, Howard PR, et al. Laboratory methods and quality assurance in the Cardiovascular Health Study. Clin Chem 1995;41:264-270. [PubMed: 7874780] 
21. Holvoet P, DeBoer A, Vernstreken M, Collen D. An enzyme-linked immunosorbent assay (ELISA) for the measurement of plasmin-alpha-2-antiplasmin complex in human plasma - application to the detection of in vivo activation of the fibrinolytic system. Thromb Haemost 1986;56:124-127. [PubMed: 2433784]

22. Agatston AS, Janowitz WR, Hildner FJ, et al. Quantification of coronary artery calcium using ultrafast computed tomography. J Am Coll Cardiol 1990;15:827-832. [PubMed: 2407762]

23. Yaghoubi S, Tang W, Wang S, et al. Offline assessment of atherosclerotic coronary calcium from electron beam tomograms. Am J Cardiac Imag 1995;9:231-236.

24. O'Leary DH, Polak JF, Wolfson SK Jr, et al. Use of sonography to evaluate carotid atherosclerosis in the elderly: The Cardiovascular Health Study. Stroke 1991;22:1155-1163. [PubMed: 1926258] 


\section{TABLE I}

Baseline Risk Factor Levels (Mean (SEM) or Percent) by Quartile of D-Dimer, MESA, 2000-2002

\begin{tabular}{|c|c|c|c|c|}
\hline \multirow[b]{2}{*}{ Baseline Factor } & \multicolumn{4}{|c|}{ D-dimer Quartiles } \\
\hline & $\leq 0.13 \mu \mathrm{g} / \mathrm{mL}$ & $0.14-0.20 \mu \mathrm{g} / \mathrm{mL}$ & $0.21-0.37 \mu \mathrm{g} / \mathrm{mL}$ & $>0.37 \mu \mathrm{g} / \mathrm{mL}$ \\
\hline \multicolumn{5}{|c|}{ Unadjusted Covariates } \\
\hline $\mathrm{N}$ & 1839 & 1559 & 1623 & 1370 \\
\hline Age (years) & $55.6(0.20)$ & $61.0(0.26)$ & $63.9(0.25)$ & $67.1(0.26)$ \\
\hline Male & $55.7 \%$ & $46.3 \%$ & $42.5 \%$ & $42.7 \%$ \\
\hline \multicolumn{5}{|l|}{ Race/Ethnicity } \\
\hline White & $40.9 \%$ & $42.0 \%$ & $37.4 \%$ & $32.2 \%$ \\
\hline Chinese American & $16.8 \%$ & $11.6 \%$ & $10.7 \%$ & $8.1 \%$ \\
\hline African American & $21.6 \%$ & $25.8 \%$ & $30.1 \%$ & $34.6 \%$ \\
\hline Hispanic & $20.7 \%$ & $20.6 \%$ & $21.8 \%$ & $25.1 \%$ \\
\hline \multicolumn{5}{|c|}{ Covariates adjusted for age, sex and race } \\
\hline Body mass index $\left(\mathrm{kg} / \mathrm{m}^{2}\right)$ & $27.2(0.12)$ & $28.4(0.14)$ & $28.6(0.13)$ & $29.2(0.13)$ \\
\hline Current Smoker & $11.0 \%$ & $13.5 \%$ & $13.3 \%$ & $13.6 \%$ \\
\hline Ex-Smoker & $36.9 \%$ & $38.1 \%$ & $56.3 \%$ & $33.7 \%$ \\
\hline Pack-years (total sample) & $9.9(0.53)$ & $11.6(0.59)$ & $12.0(0.54)$ & $12.6(0.57)$ \\
\hline Alcohol intake (drinks/week) & $4.2(0.20)$ & $3.4(0.22)$ & $4.2(0.20)$ & $3.9(0.21)$ \\
\hline Systolic Blood Pressure $(\mathrm{mmHg})$ & $125.9(0.48)$ & $126.5(0.54)$ & $126.2(0.49)$ & $127.9(0.52)$ \\
\hline Any Anti-hypertensive use & $31.7 \%$ & $34.8 \%$ & $33.2 \%$ & $39.4 \%$ \\
\hline LDL Cholesterol (mg/dl) & $115.5(0.77)$ & $118.5(0.85)$ & $118.2(0.78)$ & $117.3(0.83)$ \\
\hline HDL Cholesterol (mg/dl) & $53.2(0.33)$ & $50.3(0.36)$ & $50.4(0.33)$ & $49.6(0.35)$ \\
\hline Statin use & $16.1 \%$ & $15.8 \%$ & $14.3 \%$ & $13.3 \%$ \\
\hline Exercise (MET-h/week) & $25.6(0.94)$ & $26.5(1.04)$ & $27.1(0.96)$ & $24.3(1.01)$ \\
\hline \multicolumn{5}{|l|}{ Impaired Fasting } \\
\hline Glucose & $27.5 \%$ & $29.3 \%$ & $27.4 \%$ & $27.8 \%$ \\
\hline Diabetes & $13.1 \%$ & $14.3 \%$ & $14.8 \%$ & $14.0 \%$ \\
\hline Fibrinogen (mg/dL) & $325(1.7)$ & $342(1.9)$ & $352(1.7)$ & $369(1.8)$ \\
\hline Interleukin-6 (pg/mL) & $1.3(0.03)$ & $1.5(0.03)$ & $1.6(0.03)$ & $1.9(0.03)$ \\
\hline C-Reactive Protein (mg/L) & $2.6(0.14)$ & $3.3(0.15)$ & $4.1(0.14)$ & $5.0(0.15)$ \\
\hline
\end{tabular}




\section{Table II}

Hazard Ratio and 95\% Confidence Interval for Study Endpoints by Quartile of D-Dimer, MESA, 2000-2006

\begin{tabular}{|c|c|c|c|c|}
\hline \multirow[b]{2}{*}{$\begin{array}{l}\text { Outcome } \\
\text { Model }\end{array}$} & \multicolumn{4}{|c|}{ D-dimer Quartiles } \\
\hline & $\leq 0.13 \mu \mathrm{g} / \mathrm{mL}$ & $\begin{array}{c}0,13-0.20 \\
\mu \mathrm{g} / \mathrm{mL}\end{array}$ & $\begin{array}{l}0.21-0.37 \\
\mu \mathrm{g} / \mathrm{mL}\end{array}$ & $>0.37 \mu \mathrm{g} / \mathrm{mL}$ \\
\hline \multicolumn{5}{|l|}{ Total CVD } \\
\hline Events & 56 & 51 & 98 & 102 \\
\hline Person-years & 8516 & 6230 & 7251 & 6804 \\
\hline Crude & $\begin{array}{c}1.00 \\
\text { (Reference) }\end{array}$ & $\begin{array}{c}1.25 \\
(0.85-1.83)\end{array}$ & $\begin{array}{c}2.07 \\
(1.49-2.87)\end{array}$ & $\begin{array}{c}2.29 \\
(1.66-3.18)\end{array}$ \\
\hline Age, Sex and Race adjusted & $\begin{array}{c}1.00 \\
\text { (Reference) }\end{array}$ & $\begin{array}{c}1.01 \\
(0.69-1.49)\end{array}$ & $\begin{array}{c}1.41 \\
(1.00-2.00)\end{array}$ & $\begin{array}{c}1.29 \\
(0.90-1.85)\end{array}$ \\
\hline Age, Sex, Race and risk factor ${ }^{*}$ adjusted & $\begin{array}{c}1.00 \\
\text { (Reference) }\end{array}$ & $\begin{array}{c}0.92 \\
(0.62-1.35)\end{array}$ & $\begin{array}{c}1.30 \\
(0.92-1.84)\end{array}$ & $\begin{array}{c}1.08 \\
(0.75-1.55)\end{array}$ \\
\hline $\begin{array}{l}\text { Also adjusted for IL-6, Fibrinogen, } \\
\text { and CRP }\end{array}$ & $\begin{array}{c}1.00 \\
\text { (Reference) }\end{array}$ & $\begin{array}{c}0.87 \\
(0.59-1.28)\end{array}$ & $\begin{array}{c}1.20 \\
(0.84-1.70)\end{array}$ & $\begin{array}{c}0.95 \\
(0.65-1.39)\end{array}$ \\
\hline \multicolumn{5}{|l|}{$\underline{\operatorname{Hard} C H D}$} \\
\hline Events & 32 & 36 & 68 & 71 \\
\hline Person-years & 8575 & 6267 & 7329 & 6866 \\
\hline Crude & $\begin{array}{c}1.00 \\
\text { (Reference) }\end{array}$ & $\begin{array}{c}1.55 \\
(0.96-2.49)\end{array}$ & $\begin{array}{c}2.51 \\
(1.65-3.82)\end{array}$ & $\begin{array}{c}2.80 \\
(1.84-4.25)\end{array}$ \\
\hline Age, Sex and Race adjusted & $\begin{array}{c}1.00 \\
\text { (Reference) }\end{array}$ & $\begin{array}{c}1.24 \\
(0.76-2.00)\end{array}$ & $\begin{array}{c}1.69 \\
(1.09-2.62)\end{array}$ & $\begin{array}{c}1.55 \\
(0.98-2.44)\end{array}$ \\
\hline $\begin{array}{l}\text { Age, Sex, Race and risk factor } \\
\text { adjusted }\end{array}$ & $\begin{array}{c}1.00 \\
\text { (Reference) }\end{array}$ & $\begin{array}{c}1.11 \\
(0.69-1.81)\end{array}$ & $\begin{array}{c}1.53 \\
(0.98-2.38)\end{array}$ & $\begin{array}{c}1.27 \\
(0.80-2.01)\end{array}$ \\
\hline $\begin{array}{l}\text { Also adjusted for IL-6, Fibrinogen, } \\
\text { and CRP }\end{array}$ & $\begin{array}{c}1.00 \\
\text { (Reference) }\end{array}$ & $\begin{array}{c}1.05 \\
(0.64-1.71)\end{array}$ & $\begin{array}{c}1.41 \\
(0.90-2.21)\end{array}$ & $\begin{array}{c}1.11 \\
(0.69-1.79)\end{array}$ \\
\hline \multicolumn{5}{|l|}{$\underline{\text { Total Mortality }}$} \\
\hline Events & 21 & 34 & 58 & 97 \\
\hline Person-years & 8796 & 6479 & 7533 & 7124 \\
\hline Crude & $\begin{array}{c}1.00 \\
\text { (Reference) }\end{array}$ & $\begin{array}{c}2.21 \\
(1.28-3.30)\end{array}$ & $\begin{array}{c}3.26 \\
(1.98-5.37)\end{array}$ & $\begin{array}{c}5.79 \\
(3.61-9.28)\end{array}$ \\
\hline Age, Sex and Race adjusted & $\begin{array}{c}1.00 \\
\text { (Reference) }\end{array}$ & $\begin{array}{c}1.69 \\
(0.97-2.92)\end{array}$ & $\begin{array}{c}1.98 \\
(1.18-3.31)\end{array}$ & $\begin{array}{c}2.75 \\
(1.66-4.55)\end{array}$ \\
\hline $\begin{array}{l}\text { Age, Sex, Race and risk factor } \\
\text { adjusted }\end{array}$ & $\begin{array}{c}1.00 \\
\text { (Reference) }\end{array}$ & $\begin{array}{c}1.62 \\
(0.94-2.81)\end{array}$ & $\begin{array}{c}1.91 \\
(1.14-3.21)\end{array}$ & $\begin{array}{c}2.57 \\
(1.54-4.27)\end{array}$ \\
\hline $\begin{array}{l}\text { Also adjusted for IL-6, Fibrinogen, } \\
\text { and CRP }\end{array}$ & $\begin{array}{c}1.00 \\
\text { (Reference) }\end{array}$ & $\begin{array}{c}1.48 \\
(0.85-2.58)\end{array}$ & $\begin{array}{c}1.70 \\
(1.00-2.87)\end{array}$ & $\begin{array}{c}2.14 \\
(1.27-3.61)\end{array}$ \\
\hline
\end{tabular}


* Body mass index, systolic blood pressure, antihypertensive medications, LDL and HDL cholesterol, statin use, usual alcohol intake, smoking status, cigarette pack-years, exercise, and glycemia status. 


\section{Table III}

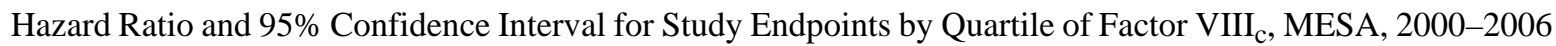

\begin{tabular}{|c|c|c|c|c|}
\hline \multirow[b]{2}{*}{$\begin{array}{l}\text { Outcome } \\
\text { Model }\end{array}$} & \multicolumn{4}{|c|}{ Factor VIII ${ }_{c}$ Quartiles } \\
\hline & $\leq 73 \%$ & $74-93 \%$ & $94-119 \%$ & $>119 \%$ \\
\hline \multicolumn{5}{|l|}{$\underline{\text { Total CVD }}$} \\
\hline Events & 46 & 59 & 94 & 91 \\
\hline Person-years & 7668 & 7083 & 7029 & 7021 \\
\hline Crude & $\begin{array}{c}1.00 \\
\text { (Reference) }\end{array}$ & $\begin{array}{c}1.08 \\
(0.75-1.53)\end{array}$ & $\begin{array}{c}1.68 \\
(1.22-2.32)\end{array}$ & $\begin{array}{c}1.63 \\
(1.18-2.25)\end{array}$ \\
\hline Age, Sex and Race adjusted & $\begin{array}{c}1.00 \\
\text { (Reference) }\end{array}$ & $\begin{array}{c}0.97 \\
(0.68-1.38)\end{array}$ & $\begin{array}{c}1.43 \\
(1.04-1.99)\end{array}$ & $\begin{array}{c}1.35 \\
(0.97-1.88)\end{array}$ \\
\hline Age, Sex, Race and risk factor ${ }^{*}$ adjusted & $\begin{array}{c}1.00 \\
\text { (Reference) }\end{array}$ & $\begin{array}{c}0.96 \\
(0.67-1.37)\end{array}$ & $\begin{array}{c}1.33 \\
(0.96-1.83)\end{array}$ & $\begin{array}{c}1.17 \\
(0.84-1.64)\end{array}$ \\
\hline Also adjusted for IL-6, Fibrinogen, and CRP & $\begin{array}{c}1.00 \\
\text { (Reference) }\end{array}$ & $\begin{array}{c}0.97 \\
(0.68-1.39)\end{array}$ & $\begin{array}{c}1.25 \\
(0.89-1.75)\end{array}$ & $\begin{array}{c}1.13 \\
(0.80-1.75)\end{array}$ \\
\hline \multicolumn{5}{|l|}{$\underline{\text { Hard CHD }}$} \\
\hline Events & 46 & 41 & 62 & 58 \\
\hline Person-years & 7720 & 7142 & 7091 & 7086 \\
\hline Crude & $\begin{array}{c}1.00 \\
\text { (Reference) }\end{array}$ & $\begin{array}{c}0.98 \\
(0.64-1.49)\end{array}$ & $\begin{array}{c}1.49 \\
(1.02-2.18)\end{array}$ & $\begin{array}{c}1.40 \\
(0.95-2.06)\end{array}$ \\
\hline Age, Sex and Race adjusted & $\begin{array}{c}1.00 \\
\text { (Reference) }\end{array}$ & $\begin{array}{c}0.89 \\
(0.58-1.36)\end{array}$ & $\begin{array}{c}1.26 \\
(0.86-1.86)\end{array}$ & $\begin{array}{c}1.14 \\
(0.77-1.69)\end{array}$ \\
\hline Age, Sex, Race and risk factor ${ }^{*}$ adjusted & $\begin{array}{c}1.00 \\
\text { (Reference) }\end{array}$ & $\begin{array}{c}0.92 \\
(0.61-1.42)\end{array}$ & $\begin{array}{c}1.21 \\
(0.82-1.79)\end{array}$ & $\begin{array}{c}1.03 \\
(0.69-1.53)\end{array}$ \\
\hline Also adjusted for IL-6, Fibrinogen, and CRP & $\begin{array}{c}1.00 \\
\text { (Reference) }\end{array}$ & $\begin{array}{c}0.93 \\
(0.61-1.43)\end{array}$ & $\begin{array}{c}1.11 \\
(0.74-1.66)\end{array}$ & $\begin{array}{c}0.97 \\
(0.64-1.47)\end{array}$ \\
\hline \multicolumn{5}{|l|}{$\underline{\text { Total Mortality }}$} \\
\hline Events & 30 & 39 & 64 & 77 \\
\hline Person-years & 7907 & 7357 & 7333 & 7336 \\
\hline Crude & $\begin{array}{c}1.00 \\
\text { (Reference) }\end{array}$ & $\begin{array}{c}1.41 \\
(0.88-2.27)\end{array}$ & $\begin{array}{c}2.32 \\
(1.51-3.59)\end{array}$ & $\begin{array}{c}2.80 \\
(1.84-4.27)\end{array}$ \\
\hline Age, Sex and Race adjusted & $\begin{array}{c}1.00 \\
\text { (Reference) }\end{array}$ & $\begin{array}{c}1.23 \\
(0.76-1.98)\end{array}$ & $\begin{array}{c}1.82 \\
(1.18-2.83)\end{array}$ & $\begin{array}{c}2.00 \\
(1.31-3.09)\end{array}$ \\
\hline Age, Sex, Race and risk factor ${ }^{*}$ adjusted & $\begin{array}{c}1.00 \\
\text { (Reference) }\end{array}$ & $\begin{array}{c}1.25 \\
(0.78-2.01)\end{array}$ & $\begin{array}{c}1.82 \\
(1.18-2.83)\end{array}$ & $\begin{array}{c}1.98 \\
(1.29-3.06)\end{array}$ \\
\hline Also adjusted for IL-6, Fibrinogen, and CRP & $\begin{array}{c}1.00 \\
\text { (Reference) }\end{array}$ & $\begin{array}{c}1.24 \\
(0.76-2.02)\end{array}$ & $\begin{array}{c}1.70 \\
(1.08-2.68)\end{array}$ & $\begin{array}{c}1.89 \\
(1.21-2.97)\end{array}$ \\
\hline
\end{tabular}


* Body mass index, systolic blood pressure, antihypertensive medications, LDL and HDL cholesterol, statin use, usual alcohol intake, smoking status, cigarette pack-years, exercise, and glycemia status. 


\section{Table IV}

Hazard Ratio and 95\% Confidence Interval for Study Endpoints by Quartile of Plasmin-Antiplasmin (PAP) Complex, MESA, 2000-2006

\begin{tabular}{|c|c|c|c|c|}
\hline \multirow[b]{2}{*}{$\begin{array}{l}\text { Outcome } \\
\text { Model }\end{array}$} & \multicolumn{4}{|c|}{ PAP Quartiles } \\
\hline & $\leq 3.446 \mathrm{nM}$ & $\begin{array}{c}3.447-4.418 \\
\mathrm{nM}\end{array}$ & $\begin{array}{c}4.419-5.654 \\
\mathrm{nM}\end{array}$ & $>5.654 \mathrm{nM}$ \\
\hline \multicolumn{5}{|l|}{$\underline{\text { Total CVD }}$} \\
\hline Events & 62 & 78 & 75 & 92 \\
\hline Person-years & 7379 & 7185 & 7206 & 7031 \\
\hline Crude & $\begin{array}{c}1.00 \\
\text { (Reference) }\end{array}$ & $\begin{array}{c}1.29 \\
(0.93-1.81)\end{array}$ & $\begin{array}{c}1.25 \\
(0.89-1.74)\end{array}$ & $\begin{array}{c}1.57 \\
(1.14-2.17)\end{array}$ \\
\hline Age, Sex and Race adjusted & $\begin{array}{c}1.00 \\
\text { (Reference) }\end{array}$ & $\begin{array}{c}1.05 \\
(0.75-1.47)\end{array}$ & $\begin{array}{c}0.93 \\
(0.66-1.31)\end{array}$ & $\begin{array}{c}0.95 \\
(0.67-1.34)\end{array}$ \\
\hline Age, Sex, Race and risk factor ${ }^{*}$ adjusted & $\begin{array}{c}1.00 \\
\text { (Reference) }\end{array}$ & $\begin{array}{c}1.10 \\
(0.78-1.55)\end{array}$ & $\begin{array}{c}1.10 \\
(0.78-1.55)\end{array}$ & $\begin{array}{c}1.06 \\
(0.74-1.51)\end{array}$ \\
\hline Also adjusted for IL-6, Fibrinogen, and CRP & $\begin{array}{c}1.00 \\
\text { (Reference) }\end{array}$ & $\begin{array}{c}1.04 \\
(0.74-1.46)\end{array}$ & $\begin{array}{c}0.92 \\
(0.64-1.32)\end{array}$ & $\begin{array}{c}0.83 \\
(0.56-1.22)\end{array}$ \\
\hline \multicolumn{5}{|l|}{$\underline{\text { Hard CHD }}$} \\
\hline Events & 42 & 44 & 52 & 69 \\
\hline Person-years & 7428 & 7269 & 7271 & 7071 \\
\hline Crude & $\begin{array}{c}1.00 \\
\text { (Reference) }\end{array}$ & $\begin{array}{c}1.08 \\
(0.71-1.64)\end{array}$ & $\begin{array}{c}1.28 \\
(0.85-1.92)\end{array}$ & $\begin{array}{c}1.76 \\
(0.71-1.64)\end{array}$ \\
\hline Age, Sex and Race adjusted & $\begin{array}{c}1.00 \\
\text { (Reference) }\end{array}$ & $\begin{array}{c}0.86 \\
(0.56-1.31)\end{array}$ & $\begin{array}{c}0.93 \\
(0.61-1.42)\end{array}$ & $\begin{array}{c}1.03 \\
(0.68-1.56)\end{array}$ \\
\hline Age, Sex, Race and risk factor ${ }^{*}$ adjusted & $\begin{array}{c}1.00 \\
\text { (Reference) }\end{array}$ & $\begin{array}{c}0.88 \\
(0.57-1.35)\end{array}$ & $\begin{array}{c}1.06 \\
(0.69-1.62)\end{array}$ & $\begin{array}{c}1.10 \\
(0.72-1.68)\end{array}$ \\
\hline Also adjusted for IL-6, Fibrinogen, and CRP & $\begin{array}{c}1.00 \\
\text { (Reference) }\end{array}$ & $\begin{array}{c}0.84 \\
(0.54-1.29)\end{array}$ & $\begin{array}{c}0.91 \\
(0.59-1.42)\end{array}$ & $\begin{array}{c}0.89 \\
(0.56-1.41)\end{array}$ \\
\hline \multicolumn{5}{|l|}{$\underline{\text { Total Mortality }}$} \\
\hline Events & 24 & 50 & 52 & 84 \\
\hline Person-years & 7599 & 7508 & 7463 & 7364 \\
\hline Crude & $\begin{array}{c}1.00 \\
\text { (Reference) }\end{array}$ & $\begin{array}{c}2.12 \\
(1.30-3.44)\end{array}$ & $\begin{array}{c}2.22 \\
(1.37-3.60)\end{array}$ & $\begin{array}{c}3.66 \\
(2.32-5.76)\end{array}$ \\
\hline Age, Sex and Race adjusted & $\begin{array}{c}1.00 \\
\text { (Reference) }\end{array}$ & $\begin{array}{c}1.60 \\
(0.98-2.62)\end{array}$ & $\begin{array}{c}1.47 \\
(0.90-2.41)\end{array}$ & $\begin{array}{c}1.87 \\
(1.16-3.03)\end{array}$ \\
\hline Age, Sex, Race and risk factor ${ }^{*}$ adjusted & $\begin{array}{c}1.00 \\
\text { (Reference) }\end{array}$ & $\begin{array}{c}1.70 \\
(1.02-2.73)\end{array}$ & $\begin{array}{c}1.60 \\
(0.97-2.63)\end{array}$ & $\begin{array}{c}2.00 \\
(1.22-3.27)\end{array}$ \\
\hline Also adjusted for IL-6, Fibrinogen, and CRP & $\begin{array}{c}1.00 \\
\text { (Reference) }\end{array}$ & $\begin{array}{c}1.55 \\
(0.94-2.55)\end{array}$ & $\begin{array}{c}1.38 \\
(0.83-2.30)\end{array}$ & $\begin{array}{c}1.55 \\
(0.92-2.62)\end{array}$ \\
\hline
\end{tabular}


* Body mass index, systolic blood pressure, antihypertensive medications, LDL and HDL cholesterol, statin use, usual alcohol intake, smoking status, cigarette pack-years, exercise, and glycemia status. 